\title{
Learning from the Deaf to Enhance Learning for the Deaf
}

\author{
Jawakhir Mior Jaafar and Mac Yin Mee*
}

Faculty of Languages and Linguistics, The University of Malaya, 50603 Kuala Lumpur, Malaysia

\begin{abstract}
This paper describes the learning and teaching experiences of two Deaf students and their respective lecturer and supervisor at the Faculty of Languages and Linguistics, University of Malaya. One is a postgraduate Deaf student pursuing a Masters in Linguistics while the other is a Deaf student pursuing a $\mathrm{PhD}$. The first student is in a classroom setting involving in-front-of class teaching, open group discussions, student presentations, and written assignments. The $\mathrm{PhD}$ Deaf student requires one-on-one discussions, written and verbal feedback on written drafts, administrative reminders from the supervisor, and preparations for postgraduate seminars. Both settings are new challenges to the lecturer and the $\mathrm{PhD}$ supervisor because this is the first time Deaf students have been admitted to the Faculty of Languages and Linguistics. The lecturer was not informed that a Deaf student would be enrolled in the class; therefore, she did not have time to make necessary preparations for handling this unique teaching-learning situation. The lecturer is faced with the challenge of imparting field specific knowledge to a student who can neither hear the lectures, nor have eye contact with the lecturer; and is uncomfortable participating in class discussions. At the beginning of the semester, the lecturer assumed that the availability of a sign language interpreter should be sufficient to meet the Deaf student's needs and fulfill the learning objectives of the course. However, as the semester unfolded, problems began to surface for both Deaf students. In the absence of relevant learning support services to address these problems, the most crucial strategies proved to be having regular open discussions with the Deaf students, the hearing students, and the sign language interpreter; and making appropriate adjustments to ensure effective communication takes place. The experiences documented in this paper, although based on only two Deaf students, revealed that given the limited circumstances, simple awareness and workable adjustments to current practices can produce satisfying results for all involved. The findings of this study could be the basis for preparing better support services for other sensory impaired students as the faculty opens its doors to future enrollment of students with such disabilities.
\end{abstract}

Keywords: Deaf students, university of Malaya, postgraduate students with disabilities, teaching and learning support.

\section{INTRODUCTION}

In Malaysia, individuals who describe themselves as Deaf with a capital 'D' refer to those who belong to the Deaf community which has its own distinct culture (the Deaf culture) and whose members communicate through the medium of Bahasa Isyarat Malaysia (BIM or Malaysian Sign Language, MySL). The Deaf differentiate themselves from hearing-impaired individuals when they refer to the latter as those who have a hearing loss of any degree, are likely to wear hearing aids, and are capable of communicating through the spoken language. In this sense then, the term deaf with a small ' $d$ ' carries a broader meaning - referring to all degrees of hearing loss and would encompass the Deaf and the hearing-impaired. Malaysian Deaf culture's history can be traced back to the British colonial days. With the establishment of the Federation School for the Deaf (FSD) in Penang in 1954, education was first introduced to the Deaf [1]. In 1989, there were 2205 Deaf students in primary schools and 756 Deaf students in secondary schools [2]. Today, the number of Deaf students has increased but only a small fraction is pursuing tertiary level education in local universities.

*Address correspondence to this author at the Faculty of Languages and Linguistics, The University of Malaya, 50603 Kuala Lumpur, Malaysia;

Tel: 603 79673104; E-mail: macym@um.edu.my
The University of Malaya (UM) is the oldest university in Malaysia. With its roots in Singapore, UM was formed in 1949 with two autonomous divisions set up in 1959 , one in Singapore and the other in Kuala Lumpur. In 1961, legislation was passed and UM was established on 1 January 1962 [3, 4]. Currently, UM has four Deaf students, and two are registered at the Faculty of Languages and Linguistics (FLL): one is pursuing a Doctorate degree while the other is pursuing a Masters degree. The other two are pursuing courses in the UM Center for Continuing Education. There are no structured learning support services available for students at the UM who are Deaf. There are also no software programs, special equipment or note-takers available for the Deaf students in UM. Most of the lecturers do not know BIM; those who do have a limited knowledge of it do not know it well enough to sustain a continuous flow of communication. As such, all four Deaf students rely on their own sign language interpreters to help them in their studies; and communication between the Deaf students and the other members of the campus community is at a minimum.

The selection of students into the study programs at UM is based on merit. Regardless of the candidates' physical capabilities, students who fulfill the stipulated academic requirements of the programs are accepted by the university. There are no special concessions in the entry requirements for students with disabilities. However, candidates are required to indicate the nature of their disability (if any) on 
their application forms. This is to ensure that during the selection process, candidates with special needs are accepted into programs that have the capacity to accommodate them. Students with special needs are given special consideration where the university provides facilities to accommodate them. For instance, students with disabilities are place at the Residential Colleges nearest to their faculties. UM also has a Counseling and Guidance Unit to provide support services to students with disabilities. There are currently 25 blind students, four deaf students, and several students with physical disabilities in UM [5]. However, unlike the blind students, the Deaf students do not seek aid from the Counseling and Guidance Unit. This may be attributed to the concept of 'Deaf Pride' among the Deaf community. Deaf Pride is defined as being proud not only as a Malaysian but also as a Deaf Malaysian [6]. Even in FLL, the Deaf students rarely approach lecturers for help and there have been no requests for note-takers.

One of the reasons why so few Deaf students pursue tertiary education is their lack of academic qualifications. In Malaysia, special educational provision for the deaf is available in three settings: (i) fully residential special schools, (ii) day special schools, and (iii) special day classes or units in regular schools [2]. Since Deaf students' written and oral language is underdeveloped, it is difficult to obtain a full certificate for Sijil Pelajaran Malaysia (SPM), which is equivalent to "O-levels" or "General Certificate of Secondary Education". Hence, many Deaf students opt for vocational schools after completing Form 3 in secondary school so that they can acquire self-employable skills in consonance with the workforce needs of the country [2].

The Deaf students, who have secured a place in FLL, UM start their studies from a disadvantaged position. For Deaf students, preparing for and participating in classroom activities, accessing and processing information, and preparing assignments may all present challenges far greater than for other students. As such, support in various forms such as through the provision of appropriate equipment, procedures, and resource personnel to compensate for the lack of function that the disability presents, may be required. The fact that the Deaf student is motivated to compete with other students in pursuit of education shows his/her determination to overcome the barriers he/she may have to face during their period at university. A lecturer who has never previously had a Deaf student in her class is likely to initially find the student's presence a 'problem,' only to realize later that the Deaf student may have faced the problem before and may therefore be able to suggest 'solutions' to it. For some Deaf students, simple adjustments to the existing system or culture could be the solution to the problem(s) deemed initially daunting.

Since 2008, FLL has collaborated with the Malaysian Association of the Deaf to produce research that would create awareness as well as education enhancement for the Deaf community. In May 2009, the faculty hosted the First International Seminar on Sign Language Research, which brought deaf as well as hearing presenters from Malaysia, Hong Kong, India, the Maldives, the Philippines, Vietnam, and Thailand together, to discuss matters such as Deaf Pride, standardization of sign language, and the impact of technology on communication with individuals who are deaf.
Hence, when two Deaf students were enrolled in FLL for the 2009/2010 academic session, it was a significant and challenging beginning for FLL where Deaf education is concerned. Based on the trends in international current practices and issues in supporting Deaf students in higher education, UM is still lacking in many ways, as there are hardly any support facilities for Deaf students. Steps need to be taken to rectify this problem; academic and support staff need to be trained to provide a conducive environment to help Deaf students excel academically. Some studies on the Deaf have mentioned various tested ways of optimizing the teaching and learning of Deaf students, including using both traditional and technology based approaches. Among the strategies [7] recommended are:

- $\quad$ Provide lecture notes and other important course materials and information a week in advance to both the Deaf student and the sign language interpreter.

- $\quad$ Suggest relevant readings to accompany lectures.

- Conduct a session with the sign language interpreter before lectures to clarify issues/topics.

- Slow down when talking and speak clearly to help the sign language interpreter.

- $\quad$ Remind other students to indicate (for example by putting up their hand) that they are about to say something.

- Stop periodically to ask questions and to allow a breather for the sign language interpreter.

- Encourage other students to write down their questions to be given to the interpreter and the Deaf student so the latter can be involved in the ensuing discussion.

- $\quad$ Encourage the Deaf student to ask questions and respond to classmates' questions.

- Give the Deaf student time to compose his/her responses.

- $\quad$ Repeat important parts.

- Encourage the Deaf student to discuss issues with lecturers - always have an open dialog to benefit both sides.

- Go over lectures with the Deaf student - one-on-one.

- Provide written feedback on the Deaf student's assignments - keep the comments simple/straightforward so he/she can tell the difference between corrections and suggestions.

- Avoid putting the Deaf student on the spot by throwing a question at him/her when he/she is not prepared.

- If class participation is graded, be flexible as to what constitutes 'participation'.

- Allow some flexibility on assignment due dates.

- Discuss the possibility of the Deaf student handing in a draft of his/her assignment for comments prior to submitting the final version.

- $\quad$ Always talk to the Deaf student and not the signer.

- Use gestures and facial expressions. 
Many of these strategies are straightforward enough to be carried out even by individuals who are not trained as support service providers for Deaf students as they simply involve making conscious adjustments to existing practices. Moreover, some of these strategies can also be used to benefit hearing students in the class.

Other strategies involve using electronic tools or providing special training to interested and dedicated individuals. Among the better-known electronic systems are the Computer Aided Realtime Translation machine (CART) and C-Print. CART uses a stenotype machine with a phonetic keyboard and special software. The software is uploaded into a computer that translates the phonetic symbols (which is typed in by a specially trained typist as the speaker is speaking) into English captions almost instantaneously [8]. C-Print is a speech-to-text system to help Deaf students and hearing impaired students in educational settings [9]. C-Print works similarly to CART except the typist inputs what is being said on the spot using a system of strategies and abbreviations as the translated version of the spoken language and the type text is displayed on a computer screen which should be placed near enough to the deaf person so every word said can be read. These electronic tools, however, are less useful to students in the educational settings at UM as many lectures are conducted in Bahasa Malaysia, the national language of Malaysia. In the absence of these electronic tools, notes could also be taken by hand and some students could be trained to be competent note-takers. Having implemented some of these strategies in her class, the principal author of this paper has been able to discover which strategies are more useful for her Deaf students.

As such, this study shows how understanding the challenges that the Deaf students face, and the strengths they bring from past academic setting experiences, enables the lecturer to modify existing methods of delivering knowledge and information in extra-ordinary circumstances. Modifications made to classroom management also help to alleviate problems for the Deaf students as well as enhance the other students' learning. These strategies are still rudimentary and are based mainly on ongoing collaborations with the two Deaf students and their sign language interpreter. However, the experiences and future collaborations with these two Deaf students will help FLL to develop more effective strategies to help Deaf students so that they can maximize their learning.

\section{METHOD}

The participants of this study are two Deaf postgraduate students at FLL and their shared sign language interpreter. Supplementary information was also obtained from unstructured interviews with the participants' respective lecturer and supervisor. Participant $1(\mathrm{P} 1)$ is a 27-year-old male Chinese who was born deaf, with no known birth complications, to hearing parents. P1 is in his first semester of the Masters in Linguistics program. Participant 2 (P2) is a 46-year-old Chinese female pursuing a $\mathrm{PhD}$ degree, who was also born deaf, to hearing parents.

A case study approach using an interview protocol administered via email to the two participants was employed to gather the information required. The interview protocol was used because of the factual nature of the information required and was administered via email because it has been found to be the most efficient way of gathering the information considering the fact that the participants are Deaf and the researchers are not able to communicate with them through BIM. Information on the participants' medical history, past academic setting experiences, challenges they face in their course of study, and their views on possible adjustments that could be made to current practices in order to enhance their current academic experiences were elicited through the interviews.

Participant observations involving the principal author (who is also the lecturer) were conducted over 14 weeks on classroom interactions of P1. The principal author was also a non-participant observer during two of P2's supervision sessions. Interviews were also carried out with P2's supervisor and their sign language interpreter (P3). P3 provided information on the challenges faced as an academic support provider to the two Deaf participants. Where required, P3 was consulted to clarify the information gathered from P1 and P2. All participants were informed of the purpose of the study and oral consent was obtained to document the information they provided in an academic paper. The main purpose of this study is to highlight lessons learnt from the experiences gained and the challenges faced by the Deaf participants, the sign language interpreter, the lecturer and the supervisor as they interact with one another. As such, the observations and conclusions drawn from this study will be presented from the combined perspectives of the authors and are limited to these specific Deaf students and academic setting.

\section{RESULTS}

\section{Background on Participant 1 (P1)}

Although P1 has hearing aids and had private speaking training in English and Bahasa Malaysia from the age of three, he prefers to communicate through writing, typing, gesturing, and through BIM. As a child, P1 did not attend pre-school or kindergarten. At the age of seven, he started formal education in an urban government school where there was a special class for Deaf children under the charge of a small group of specially trained teachers capable of teaching the mainstream subjects, using coded sign language in Malay (BMKT - Bahasa Melayu Kod Tangan, Hand Coded Malay Language). While hearing children attend six years of primary education, P1 took eight years to complete his primary education. He had to do two years each for Year 1 and Year 6. He was 15 years old when he moved on to secondary school, again in a special class for Deaf children in another government school.

P1 recalled his frustration during his first six months at the school as he felt the teachers were not teaching them anything although they were very proficient in $B M K T$. There was no proper timetable and the Deaf children did little learning during school hours. Feeling dissatisfied with the situation, P1 persistently pushed the teachers to do more in educating them. He confronted the teachers and wrote numerous letters of complaint to the school authorities. His persistence soon resulted in the teachers structuring a proper study schedule for all the Deaf students at his school. Whenever a teacher was late in coming to class, P1 would go 
and remind the teacher to come to class. Whenever a teacher did not give them homework, P1 would identify exercises from the textbooks for homework and ask the teacher to tell other deaf students (including himself) in his class to do the work. When his classmates complained of too much homework, P1 would tell them homework is good for them.

P1 caused so many problems for the special class teachers that the school later suggested that he joined the mainstream class. After discussion with his mother, they jointly decided he should try it for a month. After a month, P1 did not see himself improving so he asked to stay on for another month. Eventually, P1 remained in the mainstream class until the end of the school year and came top of the class. This spurred him on to continue studying in mainstream classes for the rest of his secondary education, even though there was no sign language interpreter.

As no learning support services were provided, P1 could not understand most of what was going on in class, but that did not deter him. He used his hearing aids in class but found that he could only understand less than $10 \%$ of the lessons. He did his homework, submitted it on time and whenever an examination approached, he read the textbooks/reference books/workbooks from page to page one to two days before the examination. In the Malaysian school system, there are three exams in each academic year, so P1 read these books thoroughly three times each year. He followed this system over the first three years of secondary school and managed to do relatively well academically. However, during his upper secondary years (Forms 4 and 5), he realized that the subjects were more challenging and his previously successful study system was beginning to fail him especially for practical subjects such as Chemistry, Physics, and Additional Mathematics. Nevertheless, through sheer hard work and determination, P1 managed to pass his SPM (equivalent to O-levels) with enough credits to obtain a scholarship to pursue a diploma followed by a degree in Computer Studies at a private college. College was not easy for P1. He applied for sign language interpreting services but the college did not have the resources to provide such services. Upon graduation, he secured a job with a computer company but after two years in employment, he decided to quit and pursue a Masters in Linguistics.

\section{Background on Participant 2 (P2)}

P2's first language and language spoken at home is Mandarin and she can write in Mandarin. She is able to lip read a bit, and uses gestures, vocalizations, and writing to communicate at home (her parents are not deaf).

P2 started six years of primary school in 1970 when she was 6 years old. She had five years of secondary schooling from 1977 to 1982. She was put in a special class at her primary school and then she was transferred to a residential school set up by the Federation for the Deaf. While studying at primary and secondary levels, signing was used all the time, although some of the teachers were not very proficient signers. P2 faced no major difficulty in learning and she attributes this to her innate love for reading. P2 believes that possessing good and effective reading skills and strategies were her advantage at school. With that ability, she was able to complete the Sijil Tinggi Persekolahan Malaysia (STPMequivalent to A-levels) through a correspondence course.
With her STPM qualifications, P2 went on to study parttime for a certificate in Graphic Design. There were no sign language interpreting services available so P2 spent most days silently watching the lecturers talk without hearing or understanding a word. After class, she would discuss the lecture with the lecturer by writing down her questions and ideas. It was not until she pursued further study at Gallaudet University in the US that learning became easier. There, signing was used at all times, writing services were provided for all classes and, for the first time, P2 obtained proper feedback on her writing which helped to improve her academic writing skills. Gallaudet University also provided note-taking, interpreting, and learning support services which $\mathrm{P} 2$ received very little of when she was growing up.

\section{Background on Participant 3 (P3)}

The interview with the sign language interpreter (P3) who is providing interpreting services to P1 and P2 further confirmed the dire state of support services available for Deaf people in Malaysia. Sign language interpreting services in Malaysia are still under-developed and there are very few registered sign language interpreters. Formal training in sign language interpreting is not currently available locally or in the Asian region. Most training available in this area is carried out in an ad-hoc manner, through seminars and workshops. P3 has over 30 years experience in sign language interpreting after having obtained her 1-year Certificate in Sign Interpreting from Canada and is pro-active in keeping her skills up to date. She frequently attends seminars and conferences discussing Deaf issues at the international and national levels, either as an interpreter, a presenter, or both. As such, she is in great demand among the Deaf community in Malaysia. She also has a key role in promoting and developing the field of sign interpreting in Malaysia. P3 is passionate about her work and about the plights of the Deaf community but laments that her struggle is really challenging, as there is a lot of bureaucracy. When she does sign language interpreting for students like P1 and P2, she does more than just interpreting. On occasions, she has to address the frustrations and emotional needs of P1 and P2 when the academic challenges they face becoming too overwhelming.

\section{DISCUSSION}

\section{Participant 1}

P1 is taking Applied Linguistics, a core course in his Masters in Linguistics program. The lecturer involved, who is also the principal author of this paper, has no experience or training to deal with a Deaf student. Since the sign language interpreter is always present in class, initially, the lecturer assumed that P1's needs have been attended to. In addition, since P1 does not participate in class discussions or discuss his problems, the lecturer assumed that everything was all right and carried on as usual in class. Observations on P1's attitude and work ethos over the semester led the principal author to conclude that the many challenges P1 has faced throughout his primary and secondary education have a significant influence on how he approaches his current Masters course. He has accepted the fact that he would not have any substantial learning support services so he has stopped asking for them. 
P1 has also learnt to manage within these exceptional circumstances. Although FLL provided him with a sign language interpreter (P3) for all his classes, it is not sufficient. P3, who is also a confidante to P1, revealed that P1 often felt frustrated after each lecture because while he felt he understood the lecture, he could not synthesize and consolidate the information provided into knowledge gained. He could not transfer what he felt he knew into the written assignments. Linguistics is an area new to him and one of his major difficulties is in understanding the linguistic concepts and theories discussed during lectures. P3 too found it difficult to sign the concepts and theories as she is not familiar with the linguistic terms. In class, P1 must focus on P3 so he could not look at the lecturer or the PowerPoint presentation, or take down notes. In cases where there is no direct word-to-sign equivalent, P3 had to resort to paraphrasing the terminology, which takes longer and in the process, she missed some of the things the lecturer was saying.

As P1 has been used to resorting to his own resources, he was not in the habit of seeking help or clarification from the lecturer or from his classmates, although both were offered to him on many occasions. Lecturers tend to take an unobtrusive attitude towards his existence in class - for fear of being perceived as giving him special favors due to his disability - hence, responding only when he makes the first move. Past experiences have led P1 to survive in his own way and most of the time, in silence. P1, for example, prefers to study on his own but, at postgraduate level, this is not the best or the most effective strategy. Conversations through his sign language interpreter revealed that P1 does not ask for help because he says he does not want to burden anyone.

P1 tried to resolve his lack of understanding by reading the PowerPoint slides before the class and then referring to the slides right after the class, in order to recall what was discussed in class. He also found reading up on the topic, for the week before and after the class, a helpful strategy. Although P1 initially expressed that he was reluctant to do a PowerPoint presentation (part of the coursework is to do two presentations/seminars) and requested that he be graded based on his written work only, the lecturer convinced him to do the presentation and if he felt it was not good, he would not be graded on that. The lecturer arranged with the other students to write out a few questions to ask after the presentation. The other students' show of interest was pleasing and broke the ice between them.

Being one who is into electronic devices, P1 felt that if FLL could provide a note-taker who could type out the lecture as it is being delivered, it would be very helpful as he can then 'see' the lectures on the screen. Based on his past experiences, P1 dislikes discussing matters with the lecturer or his course-mates because he finds it frustrating trying to communicate his intentions to non-signers. P1 found it equally unsatisfying to communicate through an interpreter. He does not like group work either, but if necessary, he would let the hearing members carry on the discussion and then tell his portion of the work. Group discussion is difficult despite the services of $\mathrm{P} 3$ because many people are talking at the same time, which can be very confusing when interpreted through signing - the flow of the discussion ends up garbled and incoherent.

In light of these observations, various adjustments were made to classroom practices. Instead of face-to-face consultations with P1, the lecturer started by emailing him questions and encouraging him to email his queries. This proved quite effective in getting P1 to open up and ask for help. As his questions became more complex, the lecturer suggested communicating through on-line chatting so a realtime discussion could take place as opposed to the earlier email-respond format where P1 had to wait longer for a reply. P1 then took this a step further and suggested adding a webcam to the communication. The webcam did not really enhance the communication because, as both P1 and the lecturer were typing in their messages, not a lot of facial expressions were used. However, it did help to create a 'face-to-face' communication effect.

The lecturer also suggested other members of the class offer their lecture notes to P1 to supplement the PowerPoint slides. As P1 did not feel comfortable 'talking' with his course-mates, he was allowed to do all his assignments alone instead of in a group. Efforts in getting the other students to be more interactive with $\mathrm{P} 1$ proved to be less successful. Malaysian students are not yet receptive to the presence of students with different circumstances in their learning environment. P1 would have benefitted from discussions with his course-mates. The effort to get them to talk to one another was even less successful due to P1's own set ways he prefers to do things on his own. He did, however, create a group email for the class through which some of the students (including P1) exchange notes and send messages to one another. In many ways, this move also helped the other students to enhance their learning. Through the second half of the semester, the students were encouraged to go into the e-forum channel set up in the university Moodle system. This mode of learning is still new to UM students and, as such, not all the students had fully utilized it. However, it has the potential of being an effective learning tool for both P1 and the other students.

The semester coursework included two tasks, an 800word critical analysis of an article, to be presented using PowerPoint and then submitted in essay form; and a 2000word mini project also to be presented in PowerPoint and essay form [10]. It was soon observed that P1 did not fully understand the tasks which were given both verbally and in printed form, although he said he understood. Through P3, the lecturer requested that $\mathrm{P} 1$ email his outline for both assignments so he could be guided accordingly. Although this problem was not unique to P1, other students would usually be able to get on with the work after a few consultations with the lecturer. Since P1 did not come to discuss his work, he was given detailed feedback using the track changes tool in Word. His reply was one of appreciation as the track changes proved effective in improving his understanding of what was required. Therefore, apart from the on-line chatting, P1 received all feedback for his written work through track changes.

\section{Participant 2}

Currently $\mathrm{P} 2$ is reading for her $\mathrm{PhD}$ in Languages and Linguistics. P2 does not find supervision sessions with her 
hearing supervisor too much of a problem. Most times, she consults her supervisor via email and telephone texts, and obtains feedback in the same way. If she needs to see her supervisor face-to-face, she emails questions in advance, allowing her supervisor time to prepare her responses. When she comes in for the meeting, she uses the services of a sign language interpreter (P3), and/or the pen and paper approach to expand on the enquiry based on the supervisor's written comments. When asked what difficulties they face during supervision, both $\mathrm{P} 2$ and her supervisor indicated that they do not have a lot of problems communicating with each other. This is probably because P2, unlike P1, is more mature and has had more experience with learning. In addition, unlike $\mathrm{P} 1$ who has to make sense of lectures, class discussions and assignments, $\mathrm{P} 2$ is a $\mathrm{PhD}$ candidate whose program involves work that is more independent. Regular discussions, prepared in advanced, have been effective in getting the message to and from both parties. However, it must be noted that P2 is only a few months into her study, and she may encounter more challenging problems as her research thesis progresses. In addition, her written work (chapter drafts) would also become longer and more complex. As such, the present approach used by the supervisor may no longer work so well and may slow down the feedback process. In light of this, the methods used by the lecturer with $\mathrm{P} 1$, such as on-line chatting and track changes may be more viable approaches.

It is also worth noting that P2 completed her masters degree at Gallaudet University which is an all Deaf environment. At Gallaudet, she received state of the art teaching and learning provision, including the presence of other Deaf students to interact with on both academic and social levels. Her move from the very supportive environment at Gallaudet to UM, where provisions for her special needs are almost non-existent, forces her to make major adjustments to her learning strategies. In the interview, she expressed her constant fear of not being able to clearly communicate her research ideas to her hearing supervisor who does not sign. For this reason, she prefers to communicate via email and writing. As such, this strengthens the efficacy of the on-line chatting and track changes approaches. One of P2's frustrations is her inability to interact with other postgraduate students; the lonely process of doing $\mathrm{PhD}$ research becomes lonelier for a student like P2.

\section{Participant 3}

P3 also revealed that in the case of P1, it is very helpful for them both when the lecturer provides the lecture materials in advance so she can go through them and confer with $\mathrm{P} 1$ as to the suitable signs for particular field specific registers. It is the same with $\mathrm{P} 2$; the availability of the supervisor's notes and feedback on P2's drafts make the face-to-face consultation sessions more meaningful for P2. For P3, interpreting in the academic setting is more challenging than other settings as the students she is interpreting for are dependent on her for the knowledge they require to get through a particular course. In this sense, P3 feels it would be of great help to the Deaf students if their lecturers could make the effort to learn how to sign even at the basic level and she is always happy to conduct sign language classes for lecturers. She also feels that the other students in the class could help the Deaf students if they could make the effort to communicate with them.

Observations of classroom events revealed that most times, the other students are 'afraid' to take the initiative to communicate with P1. Even when they wanted to say something to P1, they would direct their questions meant for P1 to P3 or to the lecturer. When they were asked why this is so, most students in P1's class replied it was because they could not sign, forgetting that there are other ways of communicating with P1 (for example through writing and gesturing). Even after a lot of encouragement from the lecturer and P3, the students did not make any serious efforts to do so. Interacting with the Deaf requires a change in behavior and attitude. This will take longer than just one semester of being in the same class and requires the combined and persistent reminders from all parties concerned. For now, the communication between P1 and the other students (although infrequently) is conducted through the group email and e-forum channels. So much could be achieved academically if other students could overcome this communication barrier to include P1 and P2 in their study or research groups and even in class interactions.

P3 found the level of interpreting for P2 during the supervision sessions more challenging than the interpreting for P1's lectures. Where P1's lectures are concerned, P3 had the PowerPoint slides to refer to whenever she got stuck with difficult terminology or a concept. During supervision, although the supervisor has provided the feedback and issues to be raised in advance, new issues arise as the discussion progresses. The supervisor often writes down her questions to P2 and the interpreting is fast-paced or halting at times when confronted with ambiguous messages. This is where a well-trained note-taker, who can either write or type the dialog as it happens, would be useful. It helped that the relationship between $\mathrm{P} 2$ and $\mathrm{P} 3$ goes beyond the confines of the supervisor's office space. P2 and P3 have been friends for 23 years and since P3 is also pursuing a postgraduate degree (at a different university) they discuss their research even after the supervision sessions. Since BIM captures the total meaning of certain expressions or sentences that are common in spoken language, it can be difficult for P3 to find the appropriate word or structure to match P2's signs. In this sense, P3's knowledge and experience in the academic areas, and her constant interactions and contact with the Deaf community, are important sources for on-the-spot solutions.

\section{CONCLUSION}

The main aim of this paper is to share experiences that came in many ways unexpectedly when Deaf students enrolled at the FLL for the first time. The information gathered for this paper has made the lecturers aware of other difficulties and challenges that might hinder P1 and P2 from achieving their true potential. This has also made it possible to address some of these difficulties, and to start implementing more appropriate and effective support services for P1 and P2, and other Deaf students who may enroll at the university in the future.

Undoubtedly, learning support services are lacking at UM. There is a great and immediate need for Malaysia to move forward together with developing nations where support services for individuals with disabilities are 
concerned. Most staff lack expertise and the right training to deal with Deaf students. In line with Malaysia's aspirations to be an integrated and caring society, it is vital that steps are taken to rectify the lack of support services for the Deaf at UM so that the university can become more "friendly" as far as students with disabilities are concerned. Lecturers and other students need to get out of their comfort zones and start to unlearn habitual behavior - things that hearing people take for granted. It is important that instructors, lecturers, and students have better awareness about the needs of Deaf students so that there will be no discrimination against them. One of the lessons learned through this experience is that Deaf Pride sometimes stops the Deaf from asking for help but help is always welcomed if offered and communicated in a more relevant manner. As P1 once said: "It would take a miracle for me to learn how to speak, but hearing people can work miracles if they would only learn to sign."

What has surfaced from this experience and investigation is more than just the awareness that support services are lacking. More importantly, in lieu of what is lacking and not available immediately, simple changes and adjustments in attitude, behavior, and approach can be just as effective in enhancing learning for students like P1 and P2. This study illustrates that helping Deaf students maximize their educational experiences at the initial stage do not need elaborate or costly methods or equipment. Identifying their weaknesses and strengths would be the first step. The next step would be to use the strengths as a guide to make straightforward, relevant changes and alternative adjustments to existing teaching and learning practices.

We conclude this paper with a quotation taken from the Disability Support Services and Facilities of the University of Newcastle in Australia:

Alternative Adjustments is about providing the
opportunity for equality, not the attainment of
a particular outcome. A student with a
disability is still required to present work that
is of a recognized standard. Providing
flexibility in the process of learning does not mean that the subject standards are lowered [7].

\section{ACKNOWLEDGEMENTS}

We wish to thank Ms. Halimaton Attan from Counselling and Guidance Section, UM; Ms. Maria from the Examination Unit, UM; Mr. Norsham from Admissions and Records, UM; the Library staff at UM and Associate Professor Dr Zubaidah Ibrahim, Faculty of Languages and Linguistics. Special thanks to P1, P2 and P3 for sharing their personal experiences with us.

\section{REFERENCES}

[1] Lim L, Woo S, Chong A, et al, Eds. Understanding deaf culture: Malaysian perspectives. Kuala Lumpur: Majudiri Y Foundation for the Deaf, 2006.

[2] History of the Deaf education in Malaysia [Online]. 2007, [cited 2009 Nov 10]. Available from: http://www.mfd.org.my/public/ content.asp?1=EN\&q=EEI

[3] History of UM [Online]. 2007, [cited 2009 Aug 15]. Available from:

http://www.um.edu.my/discoverVum/historyV̈ofVum.php?int PrefLangID $=1 \&$

[4] University of Malaya Official Website [Online]. [cited 2009 Aug 12]. Available from: http://www.um.edu.my/index.php?intPrefLa ngID $=1 \&$

[5] Student Affairs and Alumni Division, University of Malaya. Student handbook 2009/2010. Kuala Lumpur: University of Malaya 2009.

[6] Thanasayan A. Wheel power: Glorious time of year. Disabled Peoples' International [Online]. 2005, [cited 2009 Nov 25]. Available from: http://v1.dpi.org/lang-en/resources/details?page= 318

[7] Hearing impairment/deafness: Services for students who are deaf or have a hearing impairment [Online]. 2009, [cited 2009 Aug 18]. Available from: http://www.newcastle.edu.au/service/disability/ disabilities/hearing/

[8] Strategies for teaching students with hearing impairments [Online]. 2005, [cited 2009 Aug 18]. Available from: http://www.as.wvu. edu/ scidis/hearing.html

[9] What is C-Print $囚$ ? [Online]. 2009, [cited 2009 Oct19]. Available from: http://www.ntid.rit.edu/cprint/whatV̈cprint.php

[10] University of Malaya, Faculty of Languages and Linguistics. Postgraduate programme handbook 2009/2010. Kuala Lumpur: University of Malaya, 2009. 